\title{
Platinum-group element geochemistry of Boradih ultramafic intrusion from the Sonakhan greenstone belt, Bastar craton
}

\author{
M.P. MANU PRASANTH ${ }^{1 *}$, J. GREGORY \\ SHELLNUTT $^{1}$ AND K.R. HARI $^{2}$ \\ ${ }^{1}$ Department of Earth Science, National Taiwan Normal \\ University, Tingzhou Road Section 4, Taipei, 11677, \\ (*correspondance: manuprasanthmp@ntnu.edu.tw) \\ ${ }^{2}$ School of Studies in Geology and Water Resource \\ Management, Pt. Ravishankar Shukla University, Raipur, \\ 492010, Chhattisgarh, India
} Taiwan

Ultramafic volcanic and intrusive rocks associated with Archean granite-greenstone belts are potential hosts for Platinium group element (PGE) deposits. In this study, we examined the PGE potential of an ultramafic intrusion from the Neoarchean Sonakhan greenstone belt (SGB) of the Bastar craton, Central India. The intrusion is primarily comprised of olivine, clinopyroxene, and chromite cumulates. The samples are characterized by low $\mathrm{SiO}_{2}(37.3-41.1 \mathrm{wt} \%)$ high $\mathrm{MgO}$ (25.2-32.17 wt \%) with varying Ni (120-1658 ppm) and $\mathrm{Cr}(362-2402 \mathrm{ppm})$ concentrations. Most of the samples exhibit elevated total PGE ( $\Sigma$ PGE $>100 \mathrm{ppb})$. Four samples show significantly higher $\Sigma$ PGE (338-543 ppb) with relatively high total Platinum group PGEs $(\Sigma \mathrm{PPGE}=292-496$ ppb) (PPGEs; Pt, Pd, Rh) compared to the Iridium group PGEs ( $\Sigma I P G E=32-52 \mathrm{ppb}$ ) (IPGEs: Ir, Ru, Os). The IPGEs, as well as the PPGEs, do not exhibit any significant correlations with $\mathrm{Mg} \#(0.76-0.79)$. The chondrite normalized PGE patterns exhibit a higher abundance of PPGEs relative to the IPGEs, which indicates retention of IPGEs in the source mantle. The absence of significant correlations with $\mathrm{Cu}$ and low $\mathrm{Cu} / \mathrm{Pd}(0.18-2.7)$ ratios indicates, lack of sulfide control over the PGE budget. A general positive correlation of PGEs with $\mathrm{Cr}$ and higher $\mathrm{Pd} / \mathrm{Pt}(0.3-2.3)$ ratios indicate the influence of $\mathrm{Cr}$-spinel ( $\mathrm{Cr} \#=0.70-0.74 ; \mathrm{Mg} \#=0.39-0.48)$ in the partitioning of PGEs. The presence of PGE enriched samples suggests the ultramafic unit of Sonakhan greenstone belt is a potential target for further prospecting. 